\title{
Continuous Irradiation with
} Alternating Red and Blue Light Enhances Plant Growth While Keeping Nutritional Quality in Lettuce

\author{
Noriko Ohtake, Masaharu Ishikura, and Hiroshi Suzuki \\ Green Project, Business Development Center, Showa Denko K. K., \\ Kawasaki 210-0858, Japan
}

\author{
Wataru Yamori ${ }^{1,2}$ \\ Graduate School of Science, The University of Tokyo, Tokyo 113-0033, \\ Japan
}

\section{Eiji Goto \\ Graduate School of Horticulture, Chiba University, Matsudo 271-8510, Japan}

Additional index words. alternating red and blue light, continuous irradiation, LED, lettuce, plant factory

\begin{abstract}
Plant factories with artificial lighting have been developed to improve food production, functional ingredients, and profitability. Intensive research has been performed to elucidate the effects of light intensity and wavelength on plant growth and nutritional quality with the use of light-emitting diodes (LEDs). In particular, the effects of monochromatic red, blue, or simultaneous red + blue light have been studied because these wavelengths are predominantly used for photosynthesis. We examined the effects of alternating red and blue light provided by LEDs over a period of 24 hours on the growth and nutritional properties of leafy lettuce. The results clearly show that alternating red and blue light accelerated plant growth significantly compared with white fluorescent lamps or red and blue LEDs at the same daily light integral. Plants grown under alternating red/blue light had a greater net assimilation rate and total and projected leaf area (an indicator of the fraction of leaf area that absorbs more light) than other plants. Additionally, alternating red and blue light maintained high concentrations of sugars, ascorbic acid, and anthocyanins in leaves. Taken together, the results indicate that continuous irradiation with alternating red and blue light could enhance growth while maintaining the nutritional quality in lettuce.
\end{abstract}

Plant factories with artificial lighting have been developed for efficient production of food crops and are now used for the commercial production of leafy greens and herbs in many countries (Kozai, 2013). As the demands for year-round production of lettuce continue to increase in the food service industry, including fast food restaurants, the efficient operation of plant factories with artificial lighting are expected to take advantage of their characteristics, which are unaffected by weather and are able to produce high yields with uniform quality year round.

\footnotetext{
Received for publication 17 Aug. 2018. Accepted for publication 17 Sept. 2018.

This study was partly supported by Japan Society for the Promotion of Science (KAKENHI Grant Number JPMJPR13BB, 16H06552 and 18H02185 to W.Y.). ${ }^{1}$ Current address: Department of Biological Sciences, Faculty of Science, The University of Tokyo, 7-3-1, Hongo, Bunkyo-ku, Tokyo, 113-0033, Japan.

${ }^{2}$ Corresponding author. E-mail: wataru.yamori@bs.s. u-tokyo.ac.jp

This is an open access article distributed under the CC BY-NC-ND license (https://creativecommons. org/licenses/by-nc-nd/4.0/).
}

Recently, intensive research has been performed to elucidate the effect of light intensity and wavelength on plant growth with the use of LEDs, which offer many advantages, including minimal electricity consumption, low heat generation, small size, and long life compared with conventional artificial lighting, such as high-pressure sodium lamps and fluorescent lamps (Ohtake et al., 2015; Tamulaitis et al., 2005). In particular, the effects of red and blue light on plant development and growth have been extensively studied because these wavelengths are predominantly absorbed by photosynthetic pigments and efficiently drive photosynthesis (Abidi et al., 2013; Massa et al., 2008; Pfündel and Baake, 1990; Yamori, 2016; Yamori and Shikanai, 2016). It has been reported that monochromatic red or blue light alone is not suitable for normal plant growth. For example, plants grown only under red light had decreased photosynthetic rate and showed abnormal growth, compared with the simultaneous red and blue light or white light (Goins et al., 1998; Wang et al., 2015). Moreover, blue light alone, especially at high intensity, caused chloroplast avoid- ance responses, which induce chloroplasts to escape from the intense light, reducing photosynthesis (Kim et al., 2004; Loreto et al., 2009; Tholen et al., 2008; Wada et al., 2003). On the other hand, simultaneous red and blue light improved photosynthesis and growth relative to red or blue light alone (Brown et al., 1995; Hogewoning et al., 2010; Li et al., 2013; Nanya et al., 2012; OhashiKaneko et al., 2006; Yorio et al., 2001). Thus, it is now recognized that multiple simultaneous light sources, such as red and blue light, are more appropriate for plant growth than monochromatic sources.

Not only the spectral composition but also the mix of irradiation (simultaneous or alternate) can affect plant growth and physiology. Jao and Fang (2004) reported that alternating red and blue light reduced growth of potato plantlets relative to simultaneous red and blue light. On the other hand, Shimokawa et al. (2014) and Chen et al. (2017) reported that alternating red and blue light could affect growth of lettuce, but the authors could not conclude whether it had benefit for plant growth compared with simultaneous red and blue light because the growth period was short or the daily light integral (DLI) and day length were not comparable among treatments. Recently, Kuno et al. (2017) showed that alternating red and blue light could enhance growth in leafy lettuce compared with simultaneous red and blue light under equal DLI and day length, but Jishi et al. (2016) showed the opposite result in cos lettuce. Thus, the effect of alternating red and blue light on plant growth and the underlying mechanisms remain to be clarified. If alternating red and blue light can enhance plant growth compared with simultaneous red and blue light and/or fluorescent lamps, it can also reduce electricity costs by shortening the time to harvest (Ohtake et al., 2015).

Here, we examined the effects of alternating red and blue light by LEDs at different intervals but at the same DLI on the growth and nutritional properties of leafy lettuce. We posed three questions: 1) Does continuous irradiation with alternating red/ blue light enhance plant growth? 2) Does it affect nutritional quality, including concentrations of sugar, ascorbic acid, and anthocyanins? 3) What mechanisms are involved in plant growth promotion by alternating red and blue light?

\section{Materials and Methods}

Plant material and cultivation conditions. Seeds of leafy lettuce (Lactuca sativa L. 'Summer Surge'; Takii Seed Co., Kyoto, Japan) were sown in sponge blocks, and the seedlings were grown at $23{ }^{\circ} \mathrm{C}$ under a photosynthetic photon flux density $(P P F D)$ of $120 \mu \mathrm{mol} \cdot \mathrm{m}^{-2} \cdot \mathrm{s}^{-1}$ provided by cool white fluorescent lamps (FHF32-EX-N-H; Panasonic Co., Ltd., Japan). At $10 \mathrm{~d}$ after sowing (DAS), the seedlings were transplanted into growth chambers equipped with similar cool white fluorescent lamps (R:G:B = 32:45:23) 


\begin{tabular}{|c|c|c|c|c|c|c|c|c|c|}
\hline \multirow{6}{*}{ 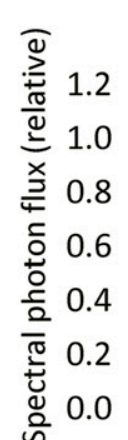 } & \multirow{6}{*}{ 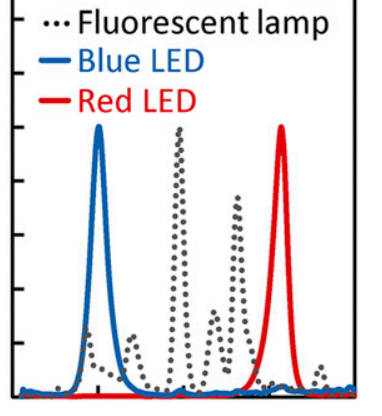 } & & $\begin{array}{c}\operatorname{PPFD}(\mathrm{R}) \\
\left(\mu \mathrm{mol} \mathrm{m} \mathrm{m}^{-2} \mathrm{~s}^{-1}\right)\end{array}$ & $\begin{array}{c}\operatorname{PPFD}(B) \\
\left(\mu \mathrm{mol} \mathrm{m} \mathrm{m}^{-2} \mathrm{~s}^{-1}\right)\end{array}$ & $\begin{array}{c}\mathrm{DLI} \\
\left(\mathrm{mol} \mathrm{m}^{-2} \mathrm{~d}^{-1}\right)\end{array}$ & \multicolumn{2}{|c|}{$\begin{array}{l}\text { Irradiation patterns } \\
\text { during } 24 \mathrm{~h}\end{array}$} & $\begin{array}{c}\text { Exp. } \\
1\end{array}$ & $\begin{array}{c}\text { Exp. } \\
2\end{array}$ \\
\hline & & W24 & \multicolumn{2}{|c|}{80} & 6.9 & \multicolumn{2}{|c|}{ FL80 (24h) } & & $\bigcirc$ \\
\hline & & $\mathrm{RB} 12 / 12$ & $90 / 30$ & $30 / 10$ & 6.9 & RB120 (12h) & RB40 (12h) & $\bigcirc$ & \\
\hline & & RB24 & 60 & 20 & 6.9 & \multicolumn{2}{|c|}{ RB80 (24h) } & O & ○ \\
\hline & & RB16 & 90 & 30 & 6.9 & \multicolumn{2}{|l|}{ RB120 (16h) } & $\bigcirc$ & \\
\hline & & R18/B6 & 80 & 80 & 6.9 & \multicolumn{2}{|l|}{ R80 (18h) } & $\bigcirc$ & \\
\hline \multicolumn{2}{|r|}{ 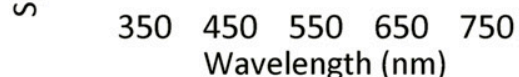 } & $\mathrm{R} 12 / \mathrm{B} 12$ & 120 & 40 & 6.9 & R120 (12h) & B40 (12h) & $\bigcirc$ & $\bigcirc$ \\
\hline
\end{tabular}

Fig. 1. Irradiation wavelengths and patterns. Plants were grown under cool white fluorescent lamps as well as red (with a peak at $660 \mathrm{~nm}$ ) and blue (with a peak at $450 \mathrm{~nm}$ ) light-emitting diodes in six irradiation patterns with equal daily light integrals: 1) constant white light at $80 \mu \mathrm{mol}^{-2} \mathrm{~m}^{-2} \cdot \mathrm{s}^{-1}$ (W24);2) constant red and blue light at $120 \mu \mathrm{mol} \cdot \mathrm{m}^{-2} \cdot \mathrm{s}^{-1}$ for $12 \mathrm{~h}$ and $40 \mu \mathrm{mol} \cdot \mathrm{m}^{-2} \mathrm{~s}^{-1}$ for $12 \mathrm{~h}(\mathrm{RB} 12 / 12) ; 3$ ) constant red and blue light at $80 \mu \mathrm{mol} \cdot \mathrm{m}^{-2} \cdot \mathrm{s}^{-1}$ (RB24); 4$)$ red and blue light for $16 \mathrm{~h}$ at $120 \mu \mathrm{mol} \cdot \mathrm{m}^{-2} \cdot \mathrm{s}^{-1}$ (RB16); 5) alternating red light at $80 \mu \mathrm{mol} \cdot \mathrm{m}^{-2} \cdot \mathrm{s}^{-1}$ for $18 \mathrm{~h}$ and blue light at $80 \mu \mathrm{mol} \cdot \mathrm{m}^{-2} \cdot \mathrm{s}^{-1}$ for $6 \mathrm{~h}$ (R18/B6); and 6) alternating red light at $120 \mu \mathrm{mol} \cdot \mathrm{m}^{-2} \cdot \mathrm{s}^{-1}$ for $12 \mathrm{~h}$ and blue light at $40 \mu \mathrm{mol} \cdot \mathrm{m}^{-2} \cdot \mathrm{s}^{-1}$ for $12 \mathrm{~h}(\mathrm{R} 12 / \mathrm{B} 12)$.

as well as blue and red LEDs (Showa Denko KK, Japan) with various irradiation patterns (Fig. 1). The DLIs of all light sources were set to $6.9 \mathrm{~mol} \cdot \mathrm{m}^{-2} \cdot \mathrm{d}^{-1}$ in all of the following six light conditions according to Shimokawa et al. (2014) (Fig. 1): (1) constant white light at $80 \mu \mathrm{mol} \cdot \mathrm{m}^{-2} \cdot \mathrm{s}^{-1}$ (W24); (2) constant red and blue light at $120 \mu \mathrm{mol} \cdot \mathrm{m}^{-2} \cdot \mathrm{s}^{-1}$ for $12 \mathrm{~h}$ and $40 \mu \mathrm{mol} \cdot \mathrm{m}^{-2} \cdot \mathrm{s}^{-1}$ for $12 \mathrm{~h}(\mathrm{RB} 12 / 12)$; (3) constant red and blue light at $80 \mu \mathrm{mol} \cdot \mathrm{m}^{-2} \cdot \mathrm{s}^{-1}$ (RB24); (4) red and blue light for $16 \mathrm{~h}$ at 120 $\mu \mathrm{mol} \cdot \mathrm{m}^{-2} \cdot \mathrm{s}^{-1}$ (RB16); (5) alternating red light at $80 \mu \mathrm{mol} \cdot \mathrm{m}^{-2} \cdot \mathrm{s}^{-1}$ for $18 \mathrm{~h}$ and blue light at $80 \mu \mathrm{mol} \cdot \mathrm{m}^{-2} \cdot \mathrm{s}^{-1}$ for $6 \mathrm{~h}(\mathrm{R} 18 / \mathrm{B} 6)$; and (6) alternating red light at $120 \mu \mathrm{mol} \cdot \mathrm{m}^{-2} \cdot \mathrm{s}^{-1}$ for $12 \mathrm{~h}$ and blue light at $40 \mu \mathrm{mol} \cdot \mathrm{m}^{-2} \cdot \mathrm{s}^{-1}$ for $12 \mathrm{~h}$ (R12/B12). The PPFD was measured with a light quantum meter (LI-250Q; LI-COR Inc., Lincoln, NE) on the surface of the culture panel, set at $30 \mathrm{~cm}$ below the LED or fluorescent lamps. Twenty plants per treatment were grown in a hydroponic culture system (TAPS-1SW, $1540 \mathrm{~mm} \mathrm{~W} \times 780 \mathrm{~mm}$ $\mathrm{D} \times 2000 \mathrm{~mm} \mathrm{H}$; Espec Mic Corp., Japan) in Otsuka House A nutrient solution (OAT Agrio Co., Ltd., Japan) with an electrical conductivity of $2.1 \pm 0.1 \mathrm{dS} \cdot \mathrm{m}^{-1}$ and a $\mathrm{pH}$ of $6.2 \pm 0.3$, which were automatically controlled by a nutrient regulator (TAPS- $1 \mathrm{~W}$; Espec Mic Corp.). The air temperature, relative humidity, and $\mathrm{CO}_{2}$ concentration were set to $23{ }^{\circ} \mathrm{C}, 70 \%$, and $1000 \mu \mathrm{mol} \cdot \mathrm{mol}^{-1}$, respectively. The planting density was $37.6 \mathrm{~m}^{-2}$ from 10 to $16 \mathrm{~d}, 26.9 \mathrm{~m}^{-2}$ from 16 to $22 \mathrm{~d}$, and $16.1 \mathrm{~m}^{-2}$ from 22 to $31 \mathrm{~d}$, which was adjusted by sampling 6 plants equidistantly at 16,22, and 31 DAS. Plants were cultivated under irradiation patterns 2 to 6 in Expt. 1 and under patterns 1, 3, and 6 in Expt. 2. Expt. 1 was used to elucidate the effects of photoperiod, light intensity, and the combination of red and blue light. On the basis of those results, we compared plant growth between alternating red and blue, simultaneous red and blue, and conventional fluorescent lamp under a 24-h photoperiod in Expt. 2. Each cultivation experiment was repeated at least twice and the representative data from the independent experiments are shown.

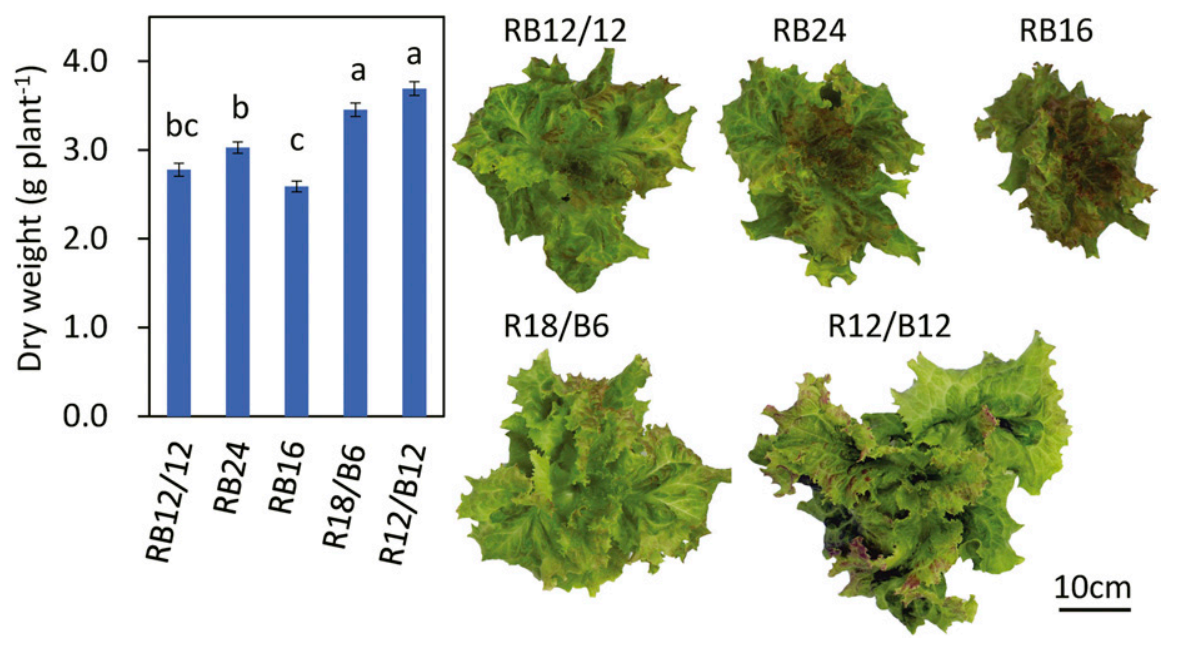

Fig. 2. Total leaf dry weight at $31 \mathrm{~d}$ after sowing and photos of each cultivation condition in Expt. 1. Plants were grown as in Fig. 1. Data are means $\pm \mathrm{SE}(\mathrm{n}=6)$. Bars labeled with the same letter are not significantly different among treatments by Tukey's honest significant difference test at $P<0.05$. Abbreviations are as in Fig. 1. Typical pictures of plant color and morphogenesis are shown.

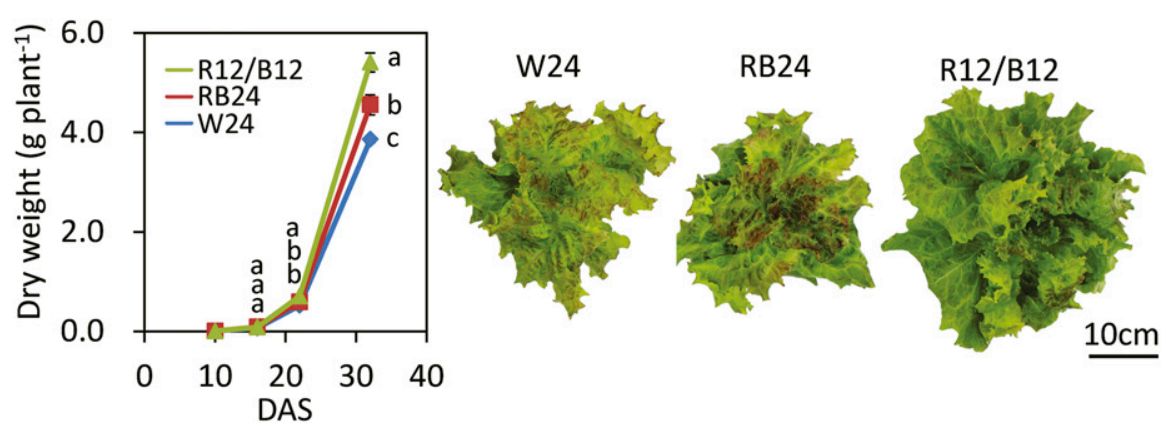

Fig. 3. Plant growth during cultivation and photos of each cultivation condition at $31 \mathrm{~d}$ after sowing in Expt. 2. Plants were grown as in Fig. 1 and harvested at 10, 16, 22, and $31 \mathrm{~d}$ after sowing. Data are means $\pm \mathrm{SE}(\mathrm{n}=6)$. Points labeled with the same letter are not significantly different among treatments by Tukey's honest significant difference test at $P<0.05$. Abbreviations are as in Fig. 1. Typical pictures of plant color and morphogenesis are shown.

Growth analysis. At 10,16, 22, and 31 DAS, plants were harvested, and the marketable fresh weights and total dry weights, projected leaf area (PLA), total leaf area (LA), number of leaves, plant height, and maximum leaf width and length were measured. PLA and LA were measured in image analysis software (LIA32 v.0.376) from digital images taken vertically downward (Maeshiro et al., 2013). Number of leaves 


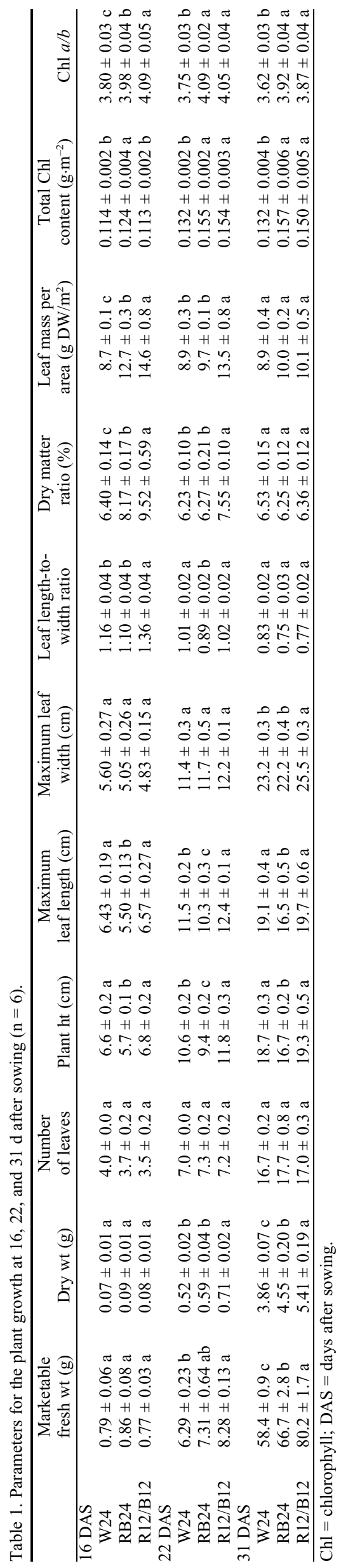

was counted for the leaves greater than $1 \mathrm{~cm}$. Dry matter ratio (DMR) was calculated as dry weight per fresh weight in the most newly expanded leaves without petiole. Leaf mass per area (LMA) was calculated as follows: $\mathrm{LMA}=$ (fresh weight of the leaf disc) $\times$ DMR / unit area. Relative growth rate (RGR), net assimilation rate (NAR), and leaf area ratio (LAR) were estimated from total dry weight and leaf area as (Blackman, 1919; Hunt, 1990; West et al., 1920; Yamori et al., 2011): RGR = $(1 / W)(\Delta W / \Delta t)=\left[\operatorname{In}\left(W_{2}\right)-\operatorname{In}\left(W_{1}\right)\right] /\left(t_{2}-t_{1}\right)$, where $W_{1}$ and $W_{2}$ are total dry weights of the whole plant at times $t_{1}$ and $t_{2} ; \mathrm{NAR}=$ $(1 / L)(\Delta W / \Delta t)=\left(W_{2}-W_{1}\right) /\left(t_{2}-t_{1}\right)\left[\operatorname{In}\left(L_{2}\right)-\right.$ $\left.\operatorname{In}\left(L_{1}\right)\right] /\left(L_{2}-L_{1}\right)$, where $L_{1}$ and $L_{2}$ are total leaf areas of the whole plant at times $t_{1}$ and $t_{2}$; $\mathrm{LAR}=\mathrm{L} / \mathrm{W}=\left[L_{1} / W_{1}+L_{2} / W_{2}\right] / 2$.

Measurements of gas exchange. Gas exchange was measured with a portable gas exchange system (LI-6400; LI-COR Inc.) as described previously (Yamori et al., 2012; Zhang et al., 2015). After $30 \mathrm{~min}$ of illumination to obtain steady-state photosynthesis, the net photosynthetic rate in the most newly expanded leaves of 31- to 35-d-old plants grown under W24 was measured under growth light conditions in Expt. 2: white light at $80 \mu \mathrm{mol} \cdot \mathrm{m}^{-2} \cdot \mathrm{s}^{-1}$ (W24), red and blue light at $80 \mu \mathrm{mol} \cdot \mathrm{m}^{-2} \cdot \mathrm{s}^{-1}$ (RB24), red light at $120 \mu \mathrm{mol} \cdot \mathrm{m}^{-2} \cdot \mathrm{s}^{-1}$ (R12/B12), and blue light at $40 \mu \mathrm{mol} \cdot \mathrm{m}^{-2} \cdot \mathrm{s}^{-1}$ (R12/B12). Then we estimated daily carbon gains by integration of the photosynthetic measurements as described previously (Chazdon, 1986; Ellsworth and Reich, 1992). Because it takes time to reach the maximum rate of photosynthesis following an increase in irradiation (Yamori et al., 2012), the estimated daily carbon gains may be slightly overestimated, although there should not be any significant differences among growth light conditions.

Nutritional quality of leafy lettuce. At 31 DAS, plants were harvested for nutritional analyses by the Japan Food Research Laboratories (http://www.jfrl.or.jp/e/index.html). Bulked samples of four or five plants per treatment were analyzed for plant moisture by the atmospheric pressure drying method, protein by Kjeldahl method, total fat by acid hydrolysis method, and ash by the direct ashing method. Contents of vitamin A, vitamin $C$ (ascorbic acid), fructose, glucose, and sucrose were quantified by high-performance liquid chromatography. Contents of free amino acids were quantified by automatic amino acid analysis. Anthocyanin and chlorophyll $(\mathrm{Chl})$ contents were analyzed in the most newly expanded leaves. Anthocyanins were extracted in hydrochloric acid/methanol $(1: 99, \mathrm{v} / \mathrm{v})$ and quantified by spectrophotometer (V-570, Jasco, Japan) according to Ubi et al. (2006). Chl was extracted in $N, N$ dimethylformamide and quantified by spectrophotometer according to Porra et al. (1989).

Statistical analysis. Values were compared between irradiation treatments by Tukey's post hoc test in Excel software (BellCurve for Excel, v. 2.15; Social Survey Research Information Co., Ltd. Tokyo, Ja- pan). Differences were considered significant at $P<0.05$.

\section{Results}

Plant growth. In Expt. 1, plant growth at 31 DAS was significantly greater under RB24 than under RB16 (Fig. 2), indicating that $24 \mathrm{~h}$ of light enhanced plant growth relative to $16 \mathrm{~h}$. Growth was significantly greater under $\mathrm{R} 18 / \mathrm{B} 6$ and R12/B12 than under RB24 and $\mathrm{RB} 12 / 12$, indicating that alternating red/blue light enhanced plant growth. Growth was marginally greater under R12/B12 than under R18/B6. These results clearly indicate that both continuous light and alternating red and blue light enhanced lettuce growth.

In Expt. 2, we performed further analysis to elucidate how alternating red and blue light improves plant growth, analyzing growth under W24, RB24, and R12/B12 at 10, 16, 22 , and 31 DAS. Plant dry weight and marketable fresh weight at 31 DAS were greatest under R12/B12, intermediate under RB24, and lowest under W24 (Fig. 3; Table 1). The number of leaves was similar among conditions. Plant height and the maximum leaf length were greater under W24
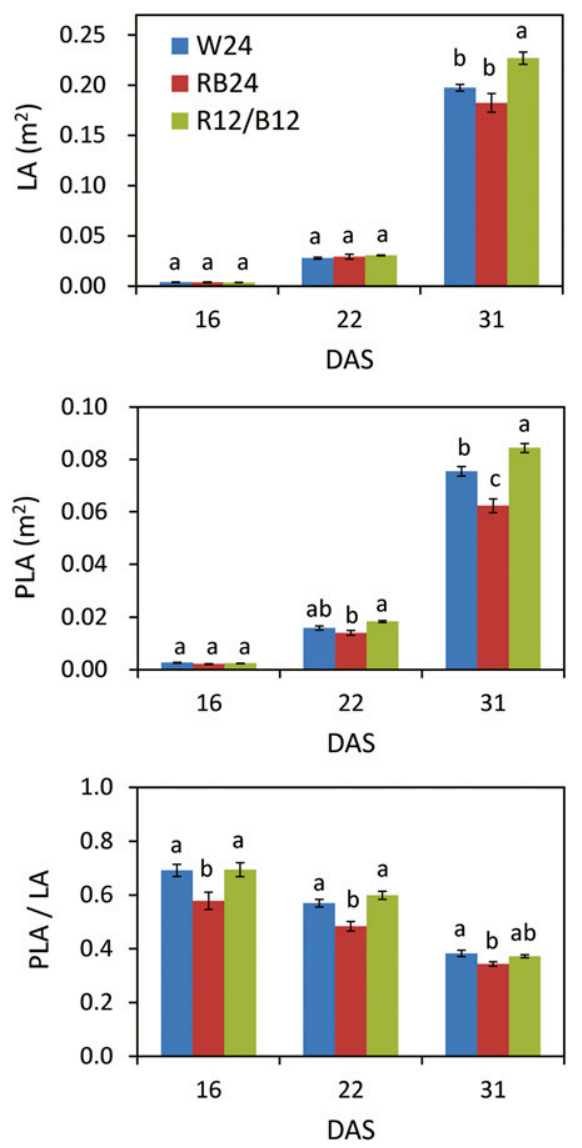

Fig. 4. Total leaf area (LA), projected leaf area (PLA) and PLA/LA in Expt. 2. Plants were grown as in Fig. 1 and measured at 16, 22, and $31 \mathrm{~d}$ after sowing. Data are means $\pm \mathrm{SE}(\mathrm{n}=6)$. Points labeled with the same letter are not significantly different among treatments by Tukey's honest significant difference test at $P<0.05$. Abbreviations are as in Fig. 1 . 


\section{0-16 DAS}

16-22 DAS
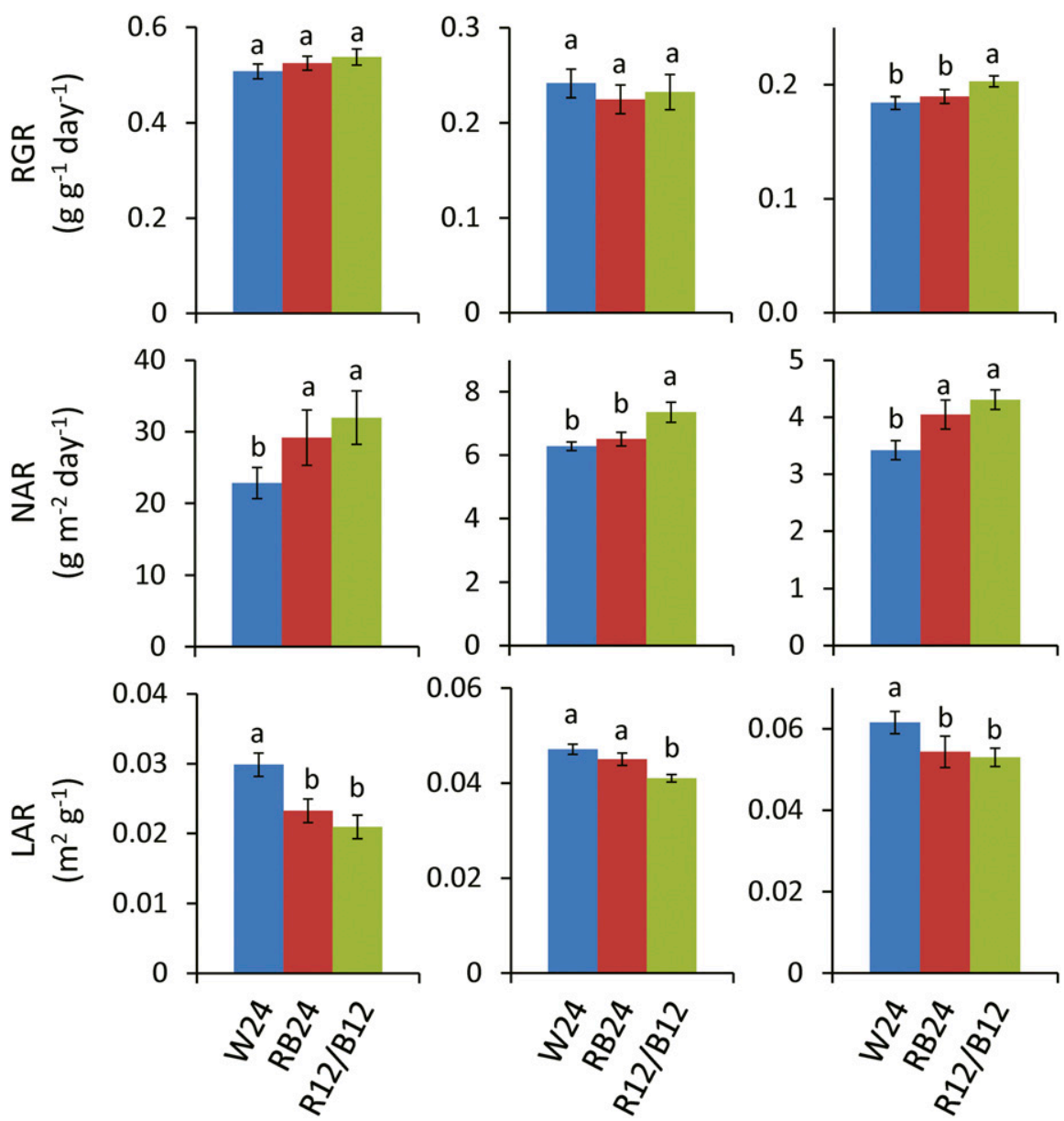

Fig. 5. Effects of irradiation patterns on plant growth in Expt. 2. Relative growth rate (RGR), net assimilation rate (NAR), and leaf area ratio (LAR) (data from Fig. 3). Cultivation experiment $(n=6)$ was repeated four times and all data were used for statistical analysis. Bars labeled with the same letter are not significantly different among the three light treatments by Tukey's honest significant difference test at $P<0.05$. Abbreviations are as in Fig. 1 .

Table 2. Daily carbon gain estimated from measurements of net photosynthetic rate. Net photosynthetic rate was measured in each light condition in Expt. 2 (Supplemental Fig. 2) and the daily carbon gain was estimated by the integration. Data are means $\pm \operatorname{SE}(n=6)$. Abbreviations as in Fig. 1.

\begin{tabular}{lc}
\hline & Daily carbon gain $\left(\mathrm{mmol} \cdot \mathrm{m}^{-2} \cdot \mathrm{d}^{-1}\right)$ \\
\hline W24 & $216.3 \pm 2.3 \mathrm{~b}$ \\
RB24 & $237.6 \pm 6.3 \mathrm{ab}$ \\
R12/B12 & $248.6 \pm 8.0 \mathrm{a}$ \\
\hline
\end{tabular}

and R12/B12 than under RB24. On the other hand, the maximum leaf width was similar among the three conditions at 16 and $22 \mathrm{DAS}$, but it was greater under R12/B12 at 31 DAS. LA was similar irrespective of growth conditions at 16 and 22 DAS, but was greatest under R12/B12 at 31 DAS (Fig. 4). PLA was greatest under R12/B12 at 22 and 31 DAS. PLA/LA was significantly greater under W24 and R12/B12 at 16 and 22 DAS and showed a similar tendency at 31 DAS. DMR and LMA in the most newly expanded leaves were significantly greatest under R12/B12 at 16 and 22 DAS (Table 1). Although there were no significant difference at 31 DAS, LMA tended to be greater under R12/B12 than under W24. Total Chl content and $\mathrm{Chl} a / b$ were greater under RB24 and R12/B12 than under W24 at 22 and 31 DAS.

There was no significant difference in RGR at $10-16$ or 16-22 DAS, but it was significantly greatest under R12/B12 at 2231 DAS (Fig. 5). NAR tended to be greatest under R12/B12, intermediate under RB24, and lowest under W24, whereas LAR showed the opposite trend. These results indicate that the enhancement of RGR under R12/B12 is attributable to an improvement in NAR, which is determined mainly by photosynthetic rate. This is supported by the significantly greater daily carbon gain under RB12/ 12 than under W24 estimated from photosynthetic measurements in each growth condition (Table 2; Supplemental Fig. 2).

Nutritional quality. The contents of protein, fat, carbohydrate, $\beta$-carotene, $\alpha$-tocopherol, and $\gamma$-tocopherol were similar among W24, RB24, and R12/B12. On the other hand, the contents of ascorbic acid, fructose, and anthocyanins tended to be greater in plants grown under R12/B12 than under other growth conditions, though only marginally significantly $(P<0.1$; Supplemental Fig. 1A). The same trends were observed in 'Red Oak' lettuce (Supplemental Fig. 1B). Thus, it is fair to say that continuous irradiation with alternating red and blue light could keep nutritional quality while enhancing plant growth in lettuce.

\section{Discussion}

Although the development of LEDs has brought new opportunities for plant factories with artificial lighting, the cost of electricity for lighting is still high. Because there is great potential to reduce costs by designing more efficient lighting systems, many studies have investigated the effects of light intensity and wavelength on plant growth (Hogewoning et al., 2010; Joshi et al., 2017; Li et al., 2013; Li and Kubota, 2009; Lin et al., 2013; Zhang et al., 2015). There has been controversy in the recent literature regarding the effect of alternating red and blue lighting on the growth of lettuce: Kuno et al. (2017) showed that alternating irradiation promoted growth compared with simultaneous irradiation of red and blue light at the same DLI and day length at 30 DAS, whereas Jishi et al. (2016) showed no significant difference between the two conditions at 21 DAS. It is highly possible that differences in cultivation stage could explain this difference. This conclusion is supported by our results, which clearly show that alternating red and blue lighting accelerated plant growth significantly compared with simultaneous red and blue, especially from 22 to 31 DAS (Figs. 2-5). Thus, the effect of alternate irradiation appears to make a significant difference to plant growth at a later stage of cultivation.

We further analyzed the mechanisms of growth promotion from the viewpoints of both photosynthesis and plant morphogenesis. Plants grown under alternating red and blue light had a high NAR (Fig. 5), which is the primary indicator of the rate of photosynthesis per unit area (Potter and Jones, 1977). This is supported by the significantly greater daily carbon gain estimated from photosynthetic measurements under alternating red and blue light than under white light (Table 2). Furthermore, LMA was significantly greatest under alternating red and blue light at the early stage and tended to be greater than under white light at 31 DAS (Table 1). Because it is commonly recognized that LMA shows good correlation with photosynthesis (Poorter et al., 2014; Reich et al., 1991), the results indicate that the plants grown under alternating red and blue light had high photosynthetic activity on the basis of leaf area, especially during early growth.

Next, we focused on the effect of alternating red and blue light on plant morphogenesis. The length-to-width ratio of the maximum leaf was greater under alternating red and blue light than under simultaneous red and blue light at 16 and 22 DAS (Table 1), indicating that alternating red and blue light promoted leaf elongation, 
which might have an advantage in light absorption. Moreover, PLA/LA was significantly greater under alternating red and blue light than under simultaneous red and blue light at 16 and 22 DAS and was marginally greater at 31 DAS (Fig. 4). Because the higher PLA/LA value means less self-shading (Furuyama et al., 2017), the result indicates that plants grown under alternating red and blue light had a lower proportion of leaf area shaded by their own leaves and thus could absorb more light than plants grown under simultaneous red and blue light. Taken together, the results show that alternating red and blue light contributed to elongated leaves with less self-shading and high photosynthetic activity, improving plant growth relative to simultaneous red and blue light or white light.

In addition, we analyzed the effect of the alternating red and blue light on nutritional quality. Generally, sugar concentration is closely related to taste (Chadwick et al., 2016; Meyers and Brewer, 2008), ascorbic acid (i.e., vitamin $\mathrm{C}$ ) is an essential antioxidant (Alasalvar et al., 2001; Kelebek et al., 2009), and anthocyanins are believed to have antioxidant properties (Lu et al., 2017; Wang and Lin, 2000). Our results indicate that the concentrations of all three were marginally greater under alternating red and blue light than under white light (Supplemental Fig. 1). Thus, we conclude that continuous irradiation with alternating red and blue light could maintain high concentrations of sugars, ascorbic acid, and anthocyanins, improving the nutritional properties of lettuce.

In this study, the DLIs were set to 6.9 $\mathrm{mol} \cdot \mathrm{m}^{-2} \cdot \mathrm{d}^{-1}$, and the ratio of red to blue was adjusted to $3: 1$ using LED light. Because it has been reported that DLI as well as the R:B ratio affect both plant growth and quality (i.e., phytochemicals) (Goto, 2012), further research is needed to optimize DLI and the R: $B$ ratio to maximize plant growth and quality in a commercial plant factory.

\section{Literature Cited}

Abidi, F., T. Girault, O. Douillet, G. Guillemain, G. Sintes, M. Laffaire, H. Ben Ahmed, S. Smiti, L. Huché-Thélier, and N. Leduc. 2013. Blue light effects on rose photosynthesis and photomorphogenesis. Plant Biol. 15:67-74.

Alasalvar, C., J.M. Grigor, D. Zhang, P.C. Quantick, and F. Shahidi. 2001. Comparison of volatiles, phenolics, sugars, antioxidant vitamins, and sensory quality of different colored carrot varieties. J. Agr. Food Chem. 49:1410-1416.

Blackman, V.H. 1919. The compound interest law and plant growth. Ann. Bot. (Lond.) 33:353360.

Brown, C.S., A.C. Schuerger, and J.C. Sager. 1995. Growth and photomorphogenesis of pepper plants under red light-emitting diodes with supplemental blue or far-red lighting. J. Amer. Soc. Hort. Sci. 120:808-813.

Chadwick, M., F. Gawthrop, R.W. Michelmore, C. Wagstaff, and L. Methven. 2016. Perception of bitterness, sweetness and linking of different genotypes of lettuce. Food Chem. 197:66-74.
Chazdon, R.L. 1986. Light variation and carbon gain in rain forest understorey palms. J. Ecol. 74:995-1012.

Chen, X.L., Q.C. Yang, W.P. Song, L.C. Wang, W.Z. Guo, and X.Z. Xue. 2017. Growth and nutritional properties of lettuce affected by different alternating intervals of red and blue LED irradiation. Scientia Hort. 223:44-52.

Ellsworth, D.S. and P.B. Reich. 1992. Leaf mass per area, nitrogen content and photosynthetic carbon gain in Acer saccharum seedlings in contrasting forest light environments. Funct. Ecol. 6:423-435.

Furuyama, S., Y. Ishigami, S. Hikosaka, and E. Goto. 2017. Estimation of lighting energy consumption required for red leaf lettuce production under different blue/red ratios and light intensity conditions in a plant factory with artificial lighting. J. SHITA 29:60-67.

Goins, G.D., N.C. Yorio, M.M. Sanwo-Lewandowski, and C.S. Brown. 1998. Life cycle experiments with Arabidopsis under red light-emitting diodes (LEDs). Life Support Biosph. Sci. 5:143-149.

Goto, E. 2012. Plant production in a closed plant factory with artificial lighting. Acta Hort. 956:37-49.

Hogewoning, S.W., G. Trouwborst, H. Maljaars, H. Poorter, W. van Ieperen, and J. Harbinson. 2010. Blue light dose-responses of leaf photosynthesis, morphology, and chemical composition of Cucumis sativus grown under different combinations of red and blue light. J. Expt. Bot. 61:3107-3117.

Hunt, R. 1990. Basic growth analysis. London, Unwin Hyman.

Jao, R.C. and W. Fang. 2004. Growth of potato plantlets in vitro is different when provided concurrent versus alternating blue and red light photoperiods. HortScience 39:380-382.

Jishi, T., K. Kimura, R. Matsuda, and K. Fujiwara. 2016. Effects of temporally shifted irradiation of blue and red LED light on cos lettuce growth and morphology. Scientia Hort. 198: 227-232.

Joshi, J., G. Zhang, S. Shen, K. Supaibulwatana, C.K.A. Watanabe, and W. Yamori. 2017. A combination of downward lighting and supplemental upward lighting improves plant growth in a closed plant factory with artificial lighting. HortScience 52:831-835.

Kelebek, H., S. Selli, A. Canbas, and T. Cabaroglu. 2009. HPLC determination of organic acids, sugars, phenolic compositions and antioxidant capacity of orange juice and orange wine made from a Turkish cv. Kozan. Microchem. J. 91:187-192.

Kim, S.J., E.J. Hahn, J.W. Heo, and K.Y. Paek. 2004. Effects of LEDs on net photosynthetic rate, growth and leaf stomata of chrysanthemum plantlets in vitro. Scientia Hort. 101:143151.

Kozai, T. 2013. Plant factory in Japan-current situation and perspectives. Chron. Hortic. 53:8-11.

Kuno, Y., H. Shimizu, H. Nakashima, J. Miyasaka, and K. Ohdoi. 2017. Effects of irradiation patterns and light quality of red and blue light-emitting diodes on growth of leaf lettuce (Lactuca sativa L. 'Greenwave'). Envrion. Control Biol. 55:129-135.

Li, Q. and C. Kubota. 2009. Effects of supplemental light quality on growth and phytochemicals of baby leaf lettuce. Environ. Expt. Bot. 67:59 64.

Li, H., C. Tang, and Z. Xu. 2013. The effects of different light qualities on rapeseed (Brassica napus L.) plantlet growth and morphogenesis in vitro. Scientia Hort. 150:117-124.

Lin, K.H., M.Y. Huang, W.D. Huang, M.H. Hsu, Z.W. Yang, and C.M. Yang. 2013. The effects of red, blue, and white light-emitting diodes on the growth, development, and edible quality of hydroponically grown lettuce (Lactuca sativa L. var. capitata). Scientia Hort. 150: 86-91.

Loreto, F., T. Tsonev, and M. Centritto. 2009. The impact of blue light on leaf mesophyll conductance. J. Expt. Bot. 60:2283-2290.

Lu, N., E.L. Bernardo, C. Tippayadarapanich, M. Takagaki, N. Kagawa, and W. Yamori. 2017. Growth and accumulation of secondary metabolites in perilla as affected by photosynthetic photon flux density and electrical conductivity of the nutrient solution. Front. Plant Sci. 8:708.

Maeshiro, R., B. Kusumoto, S. Fujii, T. Shiono, and Y. Kubota. 2013. Using tree functional diversity to evaluate management impacts in a subtropical forest. Ecosphere 4:1-17.

Massa, G.D., H.H. Kim, R.M. Wheeler, and C.A Mitchell. 2008. Plant productivity in response to LED lighting. HortScience 43:1951-1956.

Meyers, B. and M.S. Brewer. 2008. Sweet taste in man: A review. J. Food Sci. 73:R81-R90.

Nanya, K., Y. Ishigami, S. Hikosaka, and E. Goto. 2012. Effects of blue and red light on stem elongation and flowering of tomato seedlings. Acta Hort. 956:261-266.

Ohashi-Kaneko, K., R. Matsuda, E. Goto, K. Fujiwara, and K. Kurata. 2006. Growth of rice plants under red light with or without supplemental blue light. Soil Sci. Plant Nutr. 52:444452.

Ohtake, N., T. Yoneda, and H. Suzuki. 2015. Comparison of plant growth and electrical power consumption between red/blue LED and fluorescent lamp in a plant factory. J. SHITA 27:213-218.

Pfündel, E. and E. Baake. 1990. A quantitative description of fluorescence excitation spectra in intact bean leaves greened under intermittent light. Photosynth. Res. 26:19-28.

Poorter, H., H. Lambers, and J.R. Evans. 2014. Trait correlation networks: A whole-plant perspective on the recently criticized leaf economic spectrum. New Phytol. 201:378-382.

Porra, R.J., W.A. Thompson, and P.E. Kriedemann. 1989. Determination of accurate extinction coefficients and simultaneous equations for assaying chlorophylls $\mathrm{a}$ and $\mathrm{b}$ extracted with four different solvents: Verification of the concentration of chlorophyll standards by atomic absorption spectroscopy. Biochim. Biophys. Acta. Bioenerget. 975:384-394.

Potter, J.R. and J.W. Jones. 1977. Leaf area partitioning as an important factor in growth. Plant Physiol. 59:10-14.

Reich, P.B., M.B. Walters, and D.S. Ellsworth. 1991. Leaf age and season influence the relationships between leaf nitrogen, leaf mass per area and photosynthesis in maple and oak trees. Plant Cell Environ. 14:251-259.

Shimokawa, A., Y. Tonooka, M. Matsumoto, H. Ara, H. Suzuki, N. Yamauchi, and M. Shigyo. 2014. Effect of alternating red and blue light irradiation generated by light emitting diodes on the growth of leaf lettuce. bioRxiv, doi: 10.1101/003103. <https://www.biorxiv.org/ content/early/2014/02/28/003103>.

Tamulaitis, G., P. Duchovskis, Z. Bliznikas, K. Breive, R. Ulinskaite, A. Brazaityte, A. Novičkovas, and A. Žukauskas. 2005. Highpower light-emitting diode based facility for plant cultivation. J. Phys. D Appl. Phys. 38: 3182 .

Tholen, D., C. Boom, K.O. Noguchi, S. Ueda, T. Katase, and I. Terashima. 2008. The chloroplast avoidance response decreases internal 
conductance to $\mathrm{CO}_{2}$ diffusion in Arabidopsis thaliana leaves. Plant Cell Environ. 31:16881700.

Ubi, B.E., C. Honda, H. Bessho, S. Kondo, M. Wada, S. Kobayashi, and T. Moriguchi. 2006. Expression analysis of anthocyanin biosynthetic genes in apple skin: Effect of UV-B and temperature. Plant Sci. 170:571-578.

Wada, M., T. Kagawa, and Y. Sato. 2003. Chloroplast movement. Annu. Rev. Plant Biol. 54:455-468.

Wang, S.Y. and H.S. Lin. 2000. Antioxidant activity in fruits and leaves of blackberry, raspberry, and strawberry varies with cultivar and developmental stage. J. Agr. Food Chem. 48:140-146.

Wang, X.Y., X.M. Xu, and J. Cui. 2015. The importance of blue light for leaf area expansion, development of photosynthetic apparatus, and chloroplast ultrastructure of Cucumis sativus grown under weak light. Photosynthetica $53: 213-222$
West, C., G.E. Briggs, and F. Kidd. 1920. Methods and significant relations in the quantitative analysis of plant growth. New Phytol. 19: 200-207.

Yamori, W. 2016. Photosynthetic response to fluctuating environments and photoprotective strategies under abiotic stress. J. Plant Res. 129:379-395.

Yamori, W. and T. Shikanai. 2016. Physiological functions of cyclic electron transport around photosystem I in sustaining photosynthesis and plant growth. Annu. Rev. Plant Biol. 67:81106.

Yamori, W., N. Sakata, Y. Suzuki, T. Shikanai, and A. Makino. 2011. Cyclic electron flow around photosystem I via chloroplast $\mathrm{NAD}(\mathrm{P}) \mathrm{H}$ dehydrogenase (NDH) complex performs a significant physiological role during photosynthesis and plant growth at low temperature in rice. Plant J. 68:966-976.

Yamori, W., C. Masumoto, H. Fukayama, and A. Makino. 2012. Rubisco activase is a key regu- lator of non-steady-state photosynthesis at any leaf temperature and, to a lesser extent, of steady-state photosynthesis at high temperature. Plant J. 71:871-880.

Yamori, W., E. Kondo, D. Sugiura, I. Terashima, Y. Suzuki, and A. Makino. 2016. Enhanced leaf photosynthesis as a target to increase grain yield: Insights from transgenic rice lines with variable Rieske FeS protein content in the Cytochrome $b_{6} / f$ complex. Plant Cell Environ. 39:80-87.

Yorio, N.C., G.D. Goins, H.R. Kagie, R.M. Wheeler, and J.C. Sager. 2001. Improving spinach, radish and lettuce growth under red light-emitting diodes (LEDs) with blue light supplementation. HortScience 36:380-383.

Zhang, G., S. Shen, M. Takagaki, T. Kozai, and W. Yamori. 2015. Supplemental upward lighting from underneath to obtain higher marketable lettuce (Lactuca sativa) leaf fresh weight by retarding senescence of outer leaves. Front. Plant Sci. 6:1110. 